\title{
Making It Local: Beacon Communities Use Health Information Technology to Optimize Care Management
}

\author{
Amy Allen, DPT, ${ }^{1}$ Terrisca R. Des Jardins, MHSA, ${ }^{2}$ Arvela Heider, PhD, ${ }^{3}$ Chatrian R. Kanger, MPH, ${ }^{4}$ \\ David F. Lobach, MD, PhD, MS, ${ }^{5}$ Lee McWilliams, MA, Jennifer M. Polello, MHPA, MCHES, \\ Alison L. Rein, MS, ${ }^{7}$ Abigail A. Schachter, BA, Ranjit Singh MB BChir, MBA, ${ }^{8}$ \\ Barbara Sorondo, MD, MBA, Megan C. Tulikangas, MPP, and Scott A. Turske, BA ${ }^{2}$
}

\begin{abstract}
Care management aims to provide cost-effective, coordinated, non-duplicative care to improve care quality, population health, and reduce costs. The 17 communities receiving funding from the Office of the National Coordinator for Health Information Technology through the Beacon Community Cooperative Agreement Program are leaders in building and strengthening their health information technology (health IT) infrastructure to provide more effective and efficient care management. This article profiles 6 Beacon Communities' health IT-enabled care management programs, highlighting the influence of local context on program strategy and design, and describing challenges, lessons learned, and policy implications for care delivery and payment reform. The unique needs (eg, disease burden, demographics), community partnerships, and existing resources and infrastructure all exerted significant influence on the overall priorities and design of each community's care management program. Though each Beacon Community needed to engage in a similar set of care management tasks-including patient identification, stratification, and prioritization; intervention; patient engagement; and evaluation - the contextual factors helped shape the specific strategies and tools used to carry out these tasks and achieve their objectives. Although providers across the country are striving to deliver standardized, high-quality care, the diverse contexts in which this care is delivered significantly influence the priorities, strategies, and design of community-based care management interventions. Gaps and challenges in implementing effective community-based care management programs include: optimizing allocation of care management services; lack of available technology tailored to care management needs; lack of standards and interoperability; integrating care management into care settings; evaluating impact; and funding and sustainability. (Population Health Management 2014;17:149-158)
\end{abstract}

\section{Introduction}

$\mathrm{C}$ ARE MANAGEMENT PROGRAMS are a common component of many ongoing health care reform efforts aimed at achieving the "triple aim" of higher quality care, improved population health, and reduced costs. ${ }^{1,2}$ Such programs typically share similar goals, but often vary widely in their priorities, design, and execution strategies. Although there is no single, authoritative definition of care management, the Center for Health Care Strategies Care Management Framework identifies 4 main components of care management: patient identification, stratification, and prioritization; intervention; evaluation; and payment/financing (Table 1$).^{3}$

\footnotetext{
${ }^{1}$ Eastern Maine Healthcare Systems, Bangor Beacon Community, Bangor, Maine.

${ }^{2}$ Southeastern Michigan Health Association, Southeast Michigan Beacon Community, Detroit, Michigan.

${ }^{3}$ HEALTHeLINK, Western New York Beacon Community, Buffalo, New York.

${ }_{5}^{4}$ Louisiana Public Health Institute, Crescent City Beacon Community, New Orleans, Louisiana.

${ }^{5}$ Southern Piedmont Beacon Community, Concord, North Carolina and Religent Health, Durham, North Carolina.

${ }^{6}$ Arcadia Solutions, Burlington, Massachusetts (formerly representing the Beacon Community of the Inland Northwest, Spokane, Washington)

${ }^{7}$ AcademyHealth, Washington, District of Columbia.

${ }^{8}$ State University of New York at Buffalo, Western New York Beacon Community, Buffalo, New York.
} 
Table 1. Care Management Framework

\begin{tabular}{|c|c|c|}
\hline $\begin{array}{l}\text { Care Management } \\
\text { Components }\end{array}$ & Definition & Tools/Strategies \\
\hline $\begin{array}{l}\text { Identification, Stratification, } \\
\text { Prioritization }\end{array}$ & $\begin{array}{l}\text { Identification, stratification, and prioritization } \\
\text { should be used to identify consumers at the } \\
\text { highest risk who offer the greatest potential } \\
\text { for improvements in health outcomes. } \\
\text { Programs should incorporate clinical and } \\
\text { nonclinical sources of information to identify } \\
\text { consumers who will most benefit from care } \\
\text { management. }\end{array}$ & $\begin{array}{l}\text { - Health risk assessments } \\
\text { - Predictive models (algorithm-driven } \\
\text { model that uses multiple inputs to predict } \\
\text { high-risk opportunities for care } \\
\text { management) } \\
\text { - Surveys (eg, Patient Health } \\
\text { Questionnaire 9, Short Form 12) } \\
\text { - Case finding (eg, chart reviews, surveys) } \\
\text { - Referrals (from member, provider, } \\
\text { community) }\end{array}$ \\
\hline Intervention & $\begin{array}{l}\text { Interventions should be tailored to meet } \\
\text { individual consumer need, respecting the role } \\
\text { of the consumer to be a decision maker in the } \\
\text { care planning process. Interventions should be } \\
\text { designed to best serve the consumer, be } \\
\text { multifaceted, improve quality and cost- } \\
\text { effectiveness, and ensure coordination of } \\
\text { care. }\end{array}$ & $\begin{array}{l}\text { - Evidence-based practices } \\
\text { - Interactive care plan, developed based on } \\
\text { consumer-set priorities } \\
\text { - Multidisciplinary care teams } \\
\text { - "Go to" person } \\
\text { - Medical home } \\
\text { - Physical/behavioral health integration } \\
\text { - Specialized patient engagement (eg, self- } \\
\text { management training) }\end{array}$ \\
\hline Evaluation & $\begin{array}{l}\text { Evaluation should include systematic } \\
\text { measurement, testing, and analysis to ensure } \\
\text { that tailored interventions improve quality, } \\
\text { efficiency, and effectiveness. Careful and } \\
\text { consistent evaluation will build the evidence } \\
\text { base in terms of what works for complex and } \\
\text { special needs populations. }\end{array}$ & $\begin{array}{l}\text { - Program evaluations } \\
\text { - Rapid-cycle micro experiments (eg, } \\
\text { continuous quality improvement, testing, } \\
\text { and program adjustments) } \\
\text { - Representative measures of quality (eg, } \\
\text { HEDIS, CAHPS) } \\
\text { - Representative measures of cost (eg, ROI } \\
\text { calculations) }\end{array}$ \\
\hline Payment/Financing & $\begin{array}{l}\text { Payment/financing should be aligned to support } \\
\text { improvements in care management by } \\
\text { rewarding consumers and providers for } \\
\text { participating in interventions/evaluations and } \\
\text { establishing accountability for quality and } \\
\text { cost. }\end{array}$ & $\begin{array}{l}\text { - Pay for performance at multiple levels } \\
\text { (eg, health plan, provider, and consumer } \\
\text { level) } \\
\text { - Share in program savings (gainsharing) } \\
\text { - Case management/medical home } \\
\text { payments }\end{array}$ \\
\hline
\end{tabular}

Source: The Center for Health Care Strategies, Inc. Care Management Definition and Framework. 2007. < http://www.chcs.org/usr_doc/ Care_Management_Framework.pdf >. Accessed December 19, 2012.

CÄHPS, Consumer Assessment of Healthcare Providers and Systems; HEDIS, Healthcare Effectiveness Data and Information Set; ROI, return on investment.

Historically, various clinical staff performed care management functions using conventional methods (eg, mail, telephone). Today, however, providers are increasingly adopting electronic health records (EHRs), and using health information exchanges (HIEs), clinical decision support, and patient registries to support care management. These tools can facilitate more active disease management, and help improve care coordination, patient safety, and communication among patients and providers. 4

The Health Information Technology for Economic and Clinical Health (HITECH) Act of 2010 authorized the Office of the National Coordinator for Health Information Technology to create the 3-year Beacon Community Cooperative Agreement Program, which provided 17 diverse communities with \$12-\$15 million each to build and strengthen their health information technology (health IT) infrastructure in support of the triple aim. As part of their efforts, many Beacon Communities have leveraged health IT to support care management goals. This article profiles the efforts of 6 Beacon Communities applying diverse strategies to design and execute their care management programs given differ- ences in local context, disease burden, existing community resources, and partnerships. It also highlights key challenges, lessons learned, and implications for health IT policy, care delivery, and payment reform.

\section{Influence of Local Context}

Though each Beacon Community approached care management differently, 3 steps were fundamental to each of their efforts and exerted significant influence over the ultimate design and priorities of their care management programs: assessing community needs, engaging local and regional partners, and taking stock of available resources.

\section{Community needs}

At the outset of the Beacon Program, community leaders assessed demographics and disease burden in their respective catchment areas to identify unique needs and opportunities for improvement (Table 2). This assessment informed care management program design by highlighting highpriority patient populations as well as strategies for their 
Table 2. Beacon Communities and Locations

Beacon Community

Bangor Beacon

Crescent City Beacon

Inland Northwest Beacon

Southeast Michigan Beacon

Southern Piedmont Beacon Western New York Beacon
Geographic Location

Bangor, Maine and 43 surrounding cities and towns in eastern-central Maine. Largely rural. New Orleans, Louisiana and 2 surrounding parishes. Urban.

Spokane, Washington, 11 surrounding counties in eastern Washington, and 5 counties in northern Idaho. Largely rural.

Detroit, Michigan and surrounding cities of Highland Park, Hamtramck, Dearborn, and Dearborn Heights. Urban.

Cabarrus, Stanly, and Rowan counties in south-central North Carolina. Mixed urban/rural. Buffalo, New York and 8 surrounding counties. Mixed urban/rural. engagement (Table 3). Despite their demographic and geographic diversity, the majority of the communities identified patients with chronic diseases such as diabetes, cardiovascular disease, and chronic respiratory disease as highest priority. These diseases are among the most prevalent and costly health problems, and can be managed using evidencebased strategies. These conditions also disproportionately affect disadvantaged or vulnerable populations, including minority, low-income, medically underserved, and/or uninsured groups.

For instance, a significant portion of the urban Southeast Michigan Beacon population is considered vulnerable; many are uninsured $(26 \%)$, are minorities $(85 \%)$, experience limited access to care, and/or are low income $(13.1 \%$ in Dearborn Heights, $47.5 \%$ in Highland Park). This community focused on improving care and outcomes related to diabetes given the high burden of disease; statewide, diabetes affects approximately $10 \%$ of the population, or about 1 million, costing Michigan $\$ 8$ billion in 2011.

In contrast, the Inland Northwest (NW) Beacon includes 16 largely rural counties in Eastern Washington and Northern Idaho. Minorities represent less than 20\% of the population, and roughly $20 \%$ live below the federal poverty level. However, as in Southeast Michigan, the Inland NW Beacon also focuses on providing care management resources to adults with type 2 diabetes, which has a prevalence rate of $7 \%$ in the community's clinics.

\section{Community partnerships}

The role of each Beacon's lead grantee, and the number and nature of their community partnerships, also influenced care management program scope and design. Most of the lead grantees had existing relationships with local partners, which provided a foundation upon which to build Beacon initiatives. All 6 Beacon grantees engaged a variety of traditional health care partners, including hospitals, medical centers, primary care practices, community clinics, and federally qualified health centers (FQHCs); 5 Beacons also partnered with health systems, and 4 worked with physician organizations (Table 4). The communities also involved nontraditional partners as stakeholders in their care management efforts, including local health departments, health IT organizations, community and faith-based organizations, quality improvement organizations, and health plans.

For instance, the Southern Piedmont Beacon Community evolved from one of North Carolina's 14 Medicaid care management networks, and was supported by a 10-year history of collaboration to deliver care management services to vulnerable populations. Through this work, the community had already built the processes and technological infrastructure that it subsequently leveraged for Beacon efforts.

The Western New York (NY) Beacon is a partnership between a historically strong HIE (HEALTHeLINK), a Robert Wood Johnson Aligning Forces for Quality grantee (P2 Collaborative), and an independent practice association (Catholic Medical Partners). The community also has built on significant prior work, motivated by a recognized need to foster collaboration around care management in a fairly fragmented provider community.

Cultivating trust relationships and partnerships was critical to the success of these care management programs; by collaborating toward a common goal of improving care and outcomes in the community, the Beacons helped mitigate concerns among competing providers, and promoted buy-in to facilitate data sharing and related activities.

\section{Community resources and infrastructure}

Existing resources (eg, staff, training capacity) and technical infrastructure (eg, EHR penetration, preexisting HIE) that could be appropriated, repurposed, or expanded to support care management also exerted significant influence on each community's program strategy and design.

Table 3. Target Diseases and Patient Populations for Beacon Community Care Management Programs

\begin{tabular}{|c|c|c|c|c|c|c|}
\hline Target Disease/Population & Bangor & $\begin{array}{l}\text { Crescent } \\
\text { City }\end{array}$ & $\begin{array}{c}\text { Inland } \\
\text { Northwest }\end{array}$ & $\begin{array}{l}\text { Southeast } \\
\text { Michigan }\end{array}$ & $\begin{array}{l}\text { Southern } \\
\text { Piedmont }\end{array}$ & $\begin{array}{c}\text { Western } \\
\text { New York }\end{array}$ \\
\hline Diabetes & $\mathrm{X}$ & $\mathrm{X}$ & $\mathrm{X}$ & $\mathrm{X}$ & $\mathrm{X}$ & $\mathrm{X}$ \\
\hline Cardiovascular Disease (CHF, Coronary Artery Disease) & $\mathrm{X}$ & $\mathrm{X}$ & & & & $\mathrm{X}$ \\
\hline COPD & $\mathrm{X}$ & & & & $\mathrm{X}$ & \\
\hline Asthma & $\mathrm{X}$ & & & & & \\
\hline Frequent or non-emergent ED/inpatient users & $\mathrm{X}$ & $\mathrm{X}$ & & $\mathrm{X}$ & $\mathrm{X}$ & \\
\hline
\end{tabular}

$\mathrm{CHF}$, congestive heart failure; COPD, chronic obstructive pulmonary disease; ED, emergency department. 
ALLEN ET AL.

Table 4. Beacon Community Partnerships

\begin{tabular}{|c|c|c|c|c|c|c|}
\hline Community Partners & Bangor & $\begin{array}{c}\text { Crescent } \\
\text { City }\end{array}$ & $\begin{array}{l}\text { Inland } \\
\text { Northwest }\end{array}$ & $\begin{array}{l}\text { Southeast } \\
\text { Michigan }\end{array}$ & $\begin{array}{l}\text { Southern } \\
\text { Piedmont }\end{array}$ & $\begin{array}{l}\text { Western } \\
\text { New York }\end{array}$ \\
\hline Hospitals/ Medical Centers & $\mathrm{X}$ & $\mathrm{X}$ & $\mathrm{X}$ & $\mathrm{X}$ & $\mathrm{X}$ & $\mathrm{X}$ \\
\hline Health/Hospital Systems & $\mathrm{X}$ & $\mathrm{X}$ & & $\mathrm{X}$ & $\mathrm{X}$ & $\mathrm{X}$ \\
\hline Community Clinics & $\mathrm{X}$ & $\mathrm{X}$ & $\mathrm{X}$ & $\mathrm{X}$ & $\mathrm{X}$ & $\mathrm{X}$ \\
\hline FQHCs & $\mathrm{X}$ & $\mathrm{X}$ & $\mathrm{X}$ & $\mathrm{X}$ & $\mathrm{X}$ & $\mathrm{X}$ \\
\hline $\begin{array}{l}\text { Primary Care / Ambulatory } \\
\text { Clinics }\end{array}$ & $\mathrm{X}$ & $\mathrm{X}$ & $\mathrm{X}$ & $\mathrm{X}$ & $\mathrm{X}$ & $\mathrm{X}$ \\
\hline Health Departments & $\mathrm{X}$ & $\mathrm{X}$ & $\mathrm{X}$ & $\mathrm{X}$ & $\mathrm{X}$ & $\mathrm{X}$ \\
\hline Health Plans/Payers & & $\mathrm{X}$ & & $\mathrm{X}$ & & $\mathrm{X}$ \\
\hline Physician Organizations & $\mathrm{X}$ & & $\mathrm{X}$ & $\mathrm{X}$ & & $\mathrm{X}$ \\
\hline Community Örganizations & $\mathrm{X}$ & $\mathrm{X}$ & $\mathrm{X}$ & $\mathrm{X}$ & & $\mathrm{X}$ \\
\hline $\begin{array}{l}\text { Quality Improvement } \\
\text { Organizations }\end{array}$ & $\mathrm{X}$ & $X$ & & $\mathrm{X}$ & & $\mathrm{X}$ \\
\hline $\begin{array}{l}\text { Health IT organizations } \\
\text { (vendors, RECs, HIEs) }\end{array}$ & $\mathrm{X}$ & $\mathrm{X}$ & $\mathrm{X}$ & $\mathrm{X}$ & $\mathrm{X}$ & $\mathrm{X}$ \\
\hline Other & $\begin{array}{l}\text { Behavioral Health; } \\
\text { Home Care; } \\
\text { Long-Term Care }\end{array}$ & & & $\begin{array}{l}\text { Employers; } \\
\text { Universities; } \\
\text { State Community } \\
\text { Health Dept. }\end{array}$ & $\begin{array}{l}\text { State } \\
\text { Medicaid } \\
\text { program }\end{array}$ & $\begin{array}{l}\text { Transplant } \\
\text { Services; } \\
\text { Home Care; } \\
\text { Long-Term Care }\end{array}$ \\
\hline
\end{tabular}

FQHC, federally qualified health center; HIE, health information exchange; IT, information technology; REC, Regional Extension Center

In all 6 communities, HIEs are an essential infrastructure element for care management, facilitating communication, care coordination, and data aggregation and analysis. The Western NY Beacon lead grantee, HEALTHeLINK, is a sustained collaboration of major hospitals and insurers that now facilitates HIE among more than 2500 providers and 30 data sources, including laboratories, radiology, hospitals, long-term care, home care, and pharmacies. Although the Inland NW did not have a formal HIE in place before the Beacon program, the lead grantee, Inland Northwest Health Services (INHS), had for 15 years hosted a shared hospital information system to exchange information related to emergency department (ED) visits and hospitalizations among the region's hospitals and primary care practices. Under the Beacon program, INHS implemented a full HIE and clinical data repository (CDR) to support broader information exchange. To date, 16 clinics and one skilled nursing facility using 4 different EHR products, as well as 16 hospitals using 3 different EHR products, are connected to the CDR.

The Bangor and Southern Piedmont Beacons both have high levels of EHR adoption and are connected to their respective statewide HIEs. The Bangor Beacon's 2 hospital systems and $\mathrm{FQHC}$ had live EHR systems when the Beacon grant was awarded, and through Maine's statewide HIE, HealthInfoNet, Bangor Beacon providers can view information on hospital encounters, medications lists, problem lists, allergies, labs, radiology, and immunizations to support care management. In Southern Piedmont, although $60 \%$ of providers use EHRs, the IT infrastructure undergirding care management relies primarily on a centralized data warehouse associated with the North Carolina Medicaid care management network. The warehouse contains Medicaid claims as well as documentation collected from care managers in the custom-designed Care Management Information System, which providers can access via a Web-based tool.

The Crescent City and Southeast Michigan Beacons did not have existing HIE infrastructure, but they developed HIEs from scratch as part of their Beacon efforts. The
Crescent City Beacon implemented the Greater New Orleans Health Information Exchange (GNOHIE) across community clinics and hospitals with a history of post-Katrina collaboration to rebuild the primary care system. The primary use cases for the GNOHIE include ED and inpatient notifications to primary care providers (PCPs), electronic specialty care referrals, and population-level risk stratification and disease monitoring. The Southeast Michigan Beacon also launched a new community HIE, BeaconLink2Health, which features an open architecture that is compatible with most EHR platforms, and feeds into a community-level CDR to facilitate population-based analytics and management.

Recognizing that IT infrastructure alone could not support care management, the Beacons also took stock of nontechnical resources (eg, staff, training capacity) to ensure that the community would be prepared to implement new tools and protocols. To this end, the Inland NW Beacon developed a Diabetes Care Coordination Readiness Assessment to characterize the clinical resources and capacity of clinics to routinely conduct care coordination. Results from each clinic's assessment are stratified by domain to match them with recommendations and resources. Initial assessment results indicated that many communities in the region lacked resources to provide intense management for moderate-tocomplex diabetes cases; only $21 \%$ of clinics had access to a Certified Diabetes Educator, and those with access noted that it was insufficient to meet growing demand. Diagnosing these limitations positioned the Inland NW Beacon to better inform care management resource needs.

\section{Care Management Program Components}

In designing care management programs to meet their unique needs, the Beacon Communities acknowledged that no single intervention would be a panacea. Rather, a range of services would be necessary to address a variety of patient and delivery system needs along the care continuum. These services correspond to the first 2 components of the 
Table 5. Patient Identification Methods

\begin{tabular}{lcccccc}
\hline Patient Identification Method & Bangor & $\begin{array}{c}\text { Crescent } \\
\text { City }\end{array}$ & $\begin{array}{c}\text { Inland } \\
\text { Northwest }\end{array}$ & $\begin{array}{c}\text { Southeast } \\
\text { Michigan }\end{array}$ & $\begin{array}{c}\text { Southern } \\
\text { Piedmont }\end{array}$ & $\begin{array}{c}\text { Western } \\
\text { New York }\end{array}$ \\
\hline Diagnosis/lab results & $\mathrm{X}$ & $\mathrm{X}$ & $\mathrm{X}$ & $\mathrm{X}$ & & $\mathrm{X}$ \\
ED/Hospital admission/transition & $\mathrm{X}$ & $\mathrm{X}$ & $\mathrm{X}$ & $\mathrm{X}$ & $\mathrm{X}$ & $\mathrm{X}$ \\
Frequent ED/ hospital utilizers & $\mathrm{X}$ & $\mathrm{X}$ & $\mathrm{X}$ & $\mathrm{X}$ & $\mathrm{X}$ & $\mathrm{X}$ \\
Regular screening & $\mathrm{X}$ & $\mathrm{X}$ & $\mathrm{X}$ & $\mathrm{X}$ & $\mathrm{X}$ & \\
Care gaps, missed appointments & $\mathrm{X}$ & $\mathrm{X}$ & $\mathrm{X}$ & $\mathrm{X}$ & $\mathrm{X}$ & $\mathrm{X}$ \\
Behavioral risk factors & $\mathrm{X}$ & $\mathrm{X}$ & $\mathrm{X}$ & $\mathrm{X}$ & $\mathrm{X}$ & $\mathrm{X}$ \\
Provider referral & & & &
\end{tabular}

ED, emergency department.

abovementioned Care Management Framework-patient identification, stratification, and prioritization; and interventionand are supported by new or expanded existing infrastructure.

\section{Patient identification, stratification, and prioritization}

Given the staff and IT resources required, it generally is not feasible to provide care management services to all patients, even within a specified target population. Therefore, it is necessary to identify those in greatest need who stand to benefit most from care management services. In the Beacon experience, these tended to be the highest risk patients, with patterns of costly service utilization (eg, preventable inpatient and ED use), or those with inconsistent access to care (eg, frequent missed appointments). Stratifying these patients by risk and/or utilization patterns has allowed care teams to prioritize allocation of limited resources.

To address the diversity of needs, risk levels, and access to care in their target populations, all 6 Beacons are using a variety of indicators to identify patients in a range of settings (Table 5). By identifying patients across the care continuum, from primary care clinics to the $\mathrm{ED}$, the Beacons aim for there to be "no wrong door" through which patients may gain access to care management services.

Although providers can simply refer patients to receive care management, all 6 Beacons also leverage registries and/ or EHRs to identify patients with a particular diagnosis (eg, diabetes) who likely would benefit from care management. Based on admission-discharge-transfer (ADT) feeds and other clinical decision support (CDS) data, Beacon providers are flagging frequent ED utilizers in real time, identifying care gaps and missed appointments, and surveying patients for social factors that hinder access to care. These CDS capabilities expand care managers' traditional role by enabling the detection of individuals at a population level who may benefit from care management, whether or not they seek care. The Southeast Michigan Beacon, for example, encourages all patients presenting to an ED to be tested for type 2 diabetes. Patients with diabetes and prediabetes who are identified through this screening process are then referred to an appropriate care setting for follow-up and further engagement, and/or to a Patient Health Navigator.

Once identified, patients are stratified according to risk levels or groups, as defined by lab results (eg, hemoglobin A1c), vital statistic values (eg, blood pressure, body mass index), and/or utilization patterns. Some of the Beacons (eg, Crescent City) use simple algorithms to assign patients to risk groups, while others (eg, Southern Piedmont) use ana- lytics software to do so. Care management services of appropriate intensity are then allocated to patients in each risk group; for instance, practices in Crescent City use CDS to refer high-risk patients to a care manager, whereas moderaterisk patients receive phone check-ins and participate in shared medical visits, and low-risk patients receive mailed reminders of needed visits and pending appointments.

\section{Intervention}

Although each Beacon Community implemented diverse care management solutions and supportive IT tools, their interventions share several similar features and components, including: multidisciplinary care teams, care coordination and provider communication, care transition management, medication management, patient tracking and monitoring, and activating and engaging patients.

\section{Multidisciplinary care teams}

To maximize impact, the Beacon Communities drew from existing clinical and nonclinical staff roles to support care management, and hired new staff to accommodate growing caseloads and interventions. Each Beacon employs multidisciplinary teams including clinicians, care managers, care coordinators, pharmacists, and other clinical and administrative staff who work together to support patient care (Table 6). The care teams aim to provide care management services to patients at the point of need, anywhere along the continuum of care: following hospital discharges, during and after ED visits, at and following primary care visits, and in patients' homes. Furthermore, the Beacons have designed education and training programs to ensure that all team members are engaged in the care management process, able to use the supportive technology, and practicing at the top of their license.

\section{Care coordination and provider communication}

Given that patients-especially those with chronic conditions-receive care from multiple providers and in multiple settings, coordinating care among those providers and settings is a critical element of care management. The Beacons are using health IT to support care coordination through enhanced provider communication and access to patient information (Table 7). In 5 Beacons, care team members use secure messaging, and all 6 leverage HIEs to exchange discrete patient information via secure, Health Insurance Portability and Accountability Act-compliant Continuity of 
Table 6. Care Management Team Members

\begin{tabular}{|c|c|c|c|c|c|c|}
\hline $\begin{array}{l}\text { Care Management Team } \\
\text { Members }\end{array}$ & Bangor & $\begin{array}{l}\text { Crescent } \\
\text { City }\end{array}$ & $\begin{array}{l}\text { Inland } \\
\text { Northwest }\end{array}$ & $\begin{array}{l}\text { Southeast } \\
\text { Michigan }\end{array}$ & $\begin{array}{l}\text { Southern } \\
\text { Piedmont }\end{array}$ & $\begin{array}{l}\text { Western } \\
\text { New York }\end{array}$ \\
\hline Nurse Care Manager & $\mathrm{X}$ & $\mathrm{X}$ & & $\mathrm{X}$ & $\mathrm{X}$ & $\mathrm{X}$ \\
\hline Inpatient Care Manager & $\mathrm{X}$ & & & & $X$ & \\
\hline Care Coordinator & $\mathrm{X}$ & $\mathrm{X}$ & $\mathrm{X}$ & $\mathrm{X}$ & & $\mathrm{X}$ \\
\hline Health Coach & $\mathrm{X}$ & $\mathrm{X}$ & & & & \\
\hline Panel Manager & $\mathrm{X}$ & & & & $\mathrm{X}$ & \\
\hline Social Worker & $\mathrm{X}$ & & & $\mathrm{X}$ & $\mathrm{X}$ & $\mathrm{X}$ \\
\hline Transition of Care Nurse & $\mathrm{X}$ & & & & $\mathrm{X}$ & $\mathrm{X}$ \\
\hline Pharmacist & $\mathrm{X}$ & $\mathrm{X}$ & & & $\mathrm{X}$ & $\mathrm{X}$ \\
\hline Health Educator & & $\mathrm{X}$ & $\mathrm{X}$ & $\mathrm{X}$ & & \\
\hline Other & $\begin{array}{l}\text { Behavioral health; } \\
\text { home care }\end{array}$ & & & $\begin{array}{l}\text { Patient Health } \\
\text { Navigator }\end{array}$ & $\begin{array}{l}\text { Pharmacy } \\
\text { technicians }\end{array}$ & \\
\hline
\end{tabular}

Care Documents (CCDs), even among providers using different EHR systems. These data can be added directly into the receiving providers' $\mathrm{EHR}$ from the $\mathrm{CCD}$ to generate a new patient record or to update an existing record.

In the Western NY Beacon, HEALTHeLINK facilitated over 188,500 CCD exchanges in 2012, representing an approximate $110 \%$ increase over 2011. HEALTHeLINK also enables providers to use a secure authentication system to access a longitudinal virtual health record (VHR) for each consenting patient, and to import that record directly into their practice EHR. There were 323,510 VHR queries performed in 2012, a 197\% increase over 2011.

The Bangor, Crescent City, Inland NW, and Western NY Beacons are using their respective HIEs to deliver lab and radiology results directly into the ordering provider's EHR, as well as into the EHR of "carbon copy" providers (ie, those designated by the ordering provider to also receive the report; for example, a specialist would typically cc [courtesy copy] the PCP). In Western NY, this system is active in 218 practices using 13 different EHR systems, with over 80,000 results delivered per month.

These approaches provide advantages over traditional means of coordinating care, giving all providers near realtime access to comprehensive patient information from multiple sources and settings. This information can be used to guide point-of-care decision making and to drive advanced functionalities including CDS and predictive analytics.

Table 7. Care Management Services and Supporting IT Tools

\begin{tabular}{|c|c|c|c|c|c|c|}
\hline Care Management Services & Bangor & $\begin{array}{c}\text { Crescent } \\
\text { City }\end{array}$ & $\begin{array}{c}\text { Inland } \\
\text { Northwest }\end{array}$ & $\begin{array}{l}\text { Southeast } \\
\text { Michigan }\end{array}$ & $\begin{array}{l}\text { Southern } \\
\text { Piedmont }\end{array}$ & $\begin{array}{c}\text { Western } \\
\text { New York }\end{array}$ \\
\hline Patient Identification/ Risk Stratification & $\mathrm{X}$ & $\mathrm{X}$ & $\mathrm{X}$ & $\mathrm{X}$ & $\mathrm{X}$ & $\mathrm{X}$ \\
\hline Disease Registry & $\mathrm{X}$ & $\mathrm{X}$ & $\mathrm{X}$ & $\mathrm{X}$ & $\mathrm{X}$ & $\mathrm{X}$ \\
\hline Population/Panel Management System & $\mathrm{X}$ & $\mathrm{X}$ & $\mathrm{X}$ & $\mathrm{X}$ & $\mathrm{X}$ & \\
\hline Care Planning & $\mathrm{X}$ & $\mathrm{X}$ & $\mathrm{X}$ & $\mathrm{X}$ & $\mathrm{X}$ & \\
\hline Appt. Scheduling & $\mathrm{X}$ & & & & $\mathrm{X}$ & $\mathrm{X}$ \\
\hline CDS & $\mathrm{X}$ & $\mathrm{X}$ & $\mathrm{X}$ & $\mathrm{X}$ & $\mathrm{X}$ & \\
\hline Health Coaching/ Patient Education & $\mathrm{X}$ & & $\mathrm{X}$ & $\mathrm{X}$ & $\mathrm{X}$ & $\mathrm{X}$ \\
\hline mHealth (texting app) & $\mathrm{X}$ & $\mathrm{X}$ & & $\mathrm{X}$ & & \\
\hline Care Coordination & $\mathrm{X}$ & $\mathrm{X}$ & $\mathrm{X}$ & $\mathrm{X}$ & $\mathrm{X}$ & $\mathrm{X}$ \\
\hline Secure Messaging & $\mathrm{X}$ & & $\mathrm{X}$ & $\mathrm{X}$ & $\mathrm{X}$ & $\mathrm{X}$ \\
\hline Continuity of Care Document & $\mathrm{X}$ & $\mathrm{X}$ & $\mathrm{X}$ & $\mathrm{X}$ & $\mathrm{X}$ & $\mathrm{X}$ \\
\hline Specialty Referrals & $\mathrm{X}$ & $\mathrm{X}$ & $\mathrm{X}$ & & & $\mathrm{X}$ \\
\hline ADT Notifications & $\mathrm{X}$ & $\mathrm{X}$ & $\mathrm{X}$ & & $\mathrm{X}$ & $\mathrm{X}$ \\
\hline Results Delivery & $\mathrm{X}$ & $\mathrm{X}$ & $\mathrm{X}$ & & & $\mathrm{X}$ \\
\hline Discharge Summaries & $\mathrm{X}$ & $\mathrm{X}$ & $\mathrm{X}$ & & & $\mathrm{X}$ \\
\hline Medication reconciliation/ management & $\mathrm{X}$ & $\mathrm{X}$ & $\mathrm{X}$ & $\mathrm{X}$ & $\mathrm{X}$ & $\mathrm{X}$ \\
\hline Patient tracking/ monitoring & $\mathrm{X}$ & & $\mathrm{X}$ & $\mathrm{X}$ & $\mathrm{X}$ & $\mathrm{X}$ \\
\hline Patient Summary Dashboard & $\mathrm{X}$ & & $\mathrm{X}$ & $\mathrm{X}$ & $\mathrm{X}$ & $\mathrm{X}$ \\
\hline Quality Reports & $\mathrm{X}$ & $\mathrm{X}$ & $\mathrm{X}$ & $\mathrm{X}$ & $\mathrm{X}$ & \\
\hline Telemedicine/ Telemonitoring & $\mathrm{X}$ & $\mathrm{X}$ & $\mathrm{X}$ & & $\mathrm{X}$ & $\mathrm{X}$ \\
\hline $\begin{array}{l}\text { Identify barriers \& facilitate access } \\
\text { to care, resources \& services }\end{array}$ & $\mathrm{X}$ & & $\mathrm{X}$ & $\mathrm{X}$ & $\mathrm{X}$ & $\mathrm{X}$ \\
\hline Other & $\begin{array}{l}\text { Behavioral } \\
\text { health }\end{array}$ & & & $\begin{array}{l}\text { Social barriers } \\
\text { to health; } \\
\text { Visit planner }\end{array}$ & $\begin{array}{l}\text { School disease } \\
\text { reports; } \\
\text { Geo-mapping }\end{array}$ & $\begin{array}{l}\text { Patient } \\
\text { Portal/PHR }\end{array}$ \\
\hline
\end{tabular}

ADT, admission-discharge-transfer; CDS, clinical decision support; IT, information technology; PHR, personal health record. 


\section{Care transitions}

Care transitions are critical points of intervention for care management programs; when not coordinated effectively, transitions can result in lapses in communication between patients and providers, medical errors, and/or overuse, underuse, and misuse of care. Traditionally, PCPs have not been notified of their patients' ED visits or hospitalizations in a timely manner or at all and, historically, discharge summaries have only been faxed to the practice upon request, sometimes days or weeks later. However, the Beacon Communities are demonstrating effective strategies to improve communication before and during care transitions using health IT.

The Bangor, Crescent City, Southern Piedmont, and Western NY Beacons are all using their HIEs to send ADT notifications and discharge summaries from EDs and hospitals to PCPs in near real time. As noted, all 6 Beacons also use CCDs to send relevant, discrete clinical data from ED visits or inpatient admissions to PCPs' EHR systems. Western NY also is supporting care transitions by creating interfaces for communication with 5 long-term care/rehabilitation organizations and 5 home care agencies.

Four Beacons-Bangor, Crescent City, Inland NW, and Western NY - are using electronic specialty care referrals to share relevant clinical summaries between PCPs and specialists in standard formats that can be incorporated into their respective EHR systems. These exchange capabilities reduce the need to request, fax, and scan patient records and re-enter information in the EHR; they also mitigate the need for patients to carry paper records by hand from one provider to the next.

\section{Care planning}

Beacon Communities also are using IT to improve care planning. Five of the Beacons implemented CDS tools to identify gaps and potential errors in care, which trigger alerts and reminders for providers.

The Inland NW Beacon designed and implemented a CDS tool to facilitate appropriate care planning based on the American Diabetes Association's Clinical Practice Guidelines. The tool applies an algorithm to data from the community CDR to stratify the patient's disease by calculating a disease progression score; it then designs a care plan based on the patient's unique risks. The care team uses this score to modify the care plan and provide patient education. For many clinics, the tool has replaced static processes for tracking preventive measures such as spreadsheets, paper records, or dated registries.

The Southeast Michigan Beacon implemented a Visit Planner, a point-of-care reference for an individual patient's set of conditions and measures. It assists the provider in treating both acute and chronic conditions with immediate access to actionable items based on the latest information and updates.

To address challenges related to scheduling follow-up appointments during off hours, the Southern Piedmont Beacon also supported creation of a Web-based tool that allows 24/7 scheduling of primary care follow-up visits.

\section{Medication management}

As medication errors have been cited as a major cause of preventable hospital readmissions, all 6 of the Beacons are using health IT for medication tracking and reconciliation, and sharing medication history between EHR systems using CCD exchange and/or the HIE. Four of the Beacons have brought pharmacists and/or pharmacy residents into the care management teams to review medication lists for patients with chronic illnesses who present at EDs as well as during transitions of care.

The Western NY Beacon has developed a medication history and reconciliation process through the HIE that includes electronic discharge medication lists from hospitals, ordered medications from long-term care/rehab facilities, and prior medications and medication claims data. Upon notification of patient discharge, pharmacists review medication information in the HIE, providing recommendations and alerting providers electronically to potential problems. Six practices are actively engaged in this pilot, and 9 more plan to enroll.

Similarly, in collaboration with the local pharmacy school, the Bangor Beacon created a Pharmacy Resident position at the participating FQHC to view patients' discrete medication fill history on the EHR patient summary page, and provide medication reconciliation for patients with 1 or more chronic conditions.

\section{Patient tracking and monitoring}

The Beacon Communities are all working to track and monitor care processes and patient outcomes. Five Beacons are using longitudinal patient summary dashboards to track patient progress and ensure that recommended care is being administered, and 4 are monitoring patients remotely via home care monitors and other telemonitoring devices. Additionally, 4 Beacons are monitoring care quality and providing regular community-wide quality reports to participating providers.

The Southern Piedmont Beacon uses EHR-integrated documentation systems to monitor summary dashboards that display clinical information and care management services. Care managers document services delivered to patients as well as questions and issues regarding patient care, which are delivered through secure bidirectional communication systems directly to the patient's PCP's EHR. In addition, care managers for Medicaid patients enter information into the statewide Care Management Information System to be shared with the patient's other providers.

Similarly, in Southeast Michigan, the CDR offers a comprehensive, longitudinal community view of patient records through the HIE. All available patient information is consolidated in 1 document to track and manage chronic conditions and display key care action items at a glance.

Bangor is using a centralized disease registry to support care management and quality improvement activities. PCPs receive disease-specific dashboards for their patient panel, rotating each month by disease. Quarterly, care managers are able to view and compare their current patient caseload with the status of the primary care practice, organization, and broader community.

\section{Engaging patients}

An essential element of care management is patient (and caregiver) engagement, often using health IT. The Beacons are working toward this objective by improving patient-provider 
communication, enhancing patient access to their clinical information, and promoting self-management.

Thirty-one practices in the Western NY Beacon have launched an EHR-linked patient portal for patients with diabetes. To date, over 500 patients have been trained to use the portal to track key health information and schedule appointments. Clinics participating in the Crescent City Beacon also are beginning to adopt patient portals to prepare for Stage 2 Meaningful Use, which requires practices to provide patient-requested clinical summaries and care plans. Not only does this facilitate engagement, but this approach is anticipated to ease the administrative burden of providing patients with such information on an ad hoc basis.

All Beacons appreciate that creation of such communications channels is necessary but not sufficient. As such, the Southern Piedmont Beacon care managers use the Patient Activation Measure tool to assess patients' level of activation $^{6}$; based on scores, they can then supply coaching resources to facilitate patients' movement to higher levels of self-activation. To meet the needs of patients with low computer proficiency, several Crescent City clinics also have begun offering computer literacy courses, which teach patients how to access their records via patient portals.

\section{Gaps and Challenges}

\section{Optimizing allocation of care management services}

As previously noted, thoughtful consideration is required to prioritize patients and allocate limited care management resources. To date, however, there is limited systematic evidence regarding optimal approaches to identify who will benefit most from care management. As a result, the Beacon Communities have implemented diverse approaches and tools to stratify and prioritize patients, often through a trial-anderror approach. Although some Beacons have implemented risk stratification tools for this purpose, in general most EHRs lack the capacity to screen, monitor, identify trends, and stratify high-risk patients. The Beacon Communities also have struggled to determine the appropriate care team caseload, which has implications for the ability to achieve significant outcome improvements for fewer patients, or less intensive interventions for more patients.

\section{Current technology is not tailored to care management needs}

In implementing these care management programs the Beacon Communities found that, at present, vendor capabilities and standards do not necessarily align with the needs of care management. As a result, they experienced challenges in integrating health IT smoothly into the care management workflow. They attribute this difficulty, in part, to a lack of specific care management functions in their health IT systems, though in some cases they were able to develop "work-arounds" to fill those gaps. In Bangor, for example, not having care manager-specific documentation in the EHR was initially a challenge; by developing, harmonizing, and sharing care manager-specific EHR forms among participating organizations, however, they have improved documentation and enhanced care manager relationships. This effort also provided Bangor Beacon leaders with a collaborative foundation on which to base further efforts; faced with care manager reluctance to use the HIE (largely because of the required second log-in), they worked together to find a solution, and currently are testing middleware to eliminate the need for this second log-in.

\section{Standards and interoperability}

As they implemented HIEs, CCD exchange, and other methods for community-wide data sharing, the Beacons found the lack of standard documentation practices and low levels of system interoperability to be significant barriers. In the Inland NW, the lack of standardization-even among common EHR products-increased the complexity and resources required to normalize data from different EHR systems to national standards before transmitting it to the CDR to drive quality reporting and CDS algorithms. The Southern Piedmont Beacon also faced challenges when implementing ADT feeds from each participating system; despite following HL7 standards, the feeds were highly variable and each required custom mapping to the receiving database. These experiences demonstrate the importance of establishing standards and specifications for documentation, data exchange, and interoperability between disparate systems. To further this aim, several Beacon Communities and EHR vendors established the EHR Vendor Affinity Group in December 2011. The group meets regularly to work toward consensus on specifications for CCD-based clinical exchange to support care transitions and to populate CDRs and disease registries.

\section{Integrating care management into care settings}

Aside from limitations in care management technology, the Beacons also encountered challenges related to workflow, buy-in, and changing team roles. The Beacons aimed to spread the care management model to other patient populations; however, they found that inconsistent adoption of care management processes and technologies among the multidisciplinary care teams (eg, because of competing priorities, lack of training) hindered implementation. Furthermore, as the care management programs entailed partnership with non-primary care teams, the Beacons found that a certain level of mutual trust and accountability was essential to coordinate care among diverse team members and settings. To foster this commitment, the Beacons provided training, resources, and troubleshooting forums, such as quality improvement coaching, workflow redesign, and live learning sessions.

The Bangor Beacon Community hosted bimonthly forums for care managers to network and share community resources, collaboratively problem solve, build relationships, and learn skills and quality improvement strategies. These forums also provided opportunities to learn about the new technology, and the care managers' feedback helped drive the development of secure messaging, capabilities for ADT alerts, HIE modifications, and care managementspecific EHR forms.

Recognizing that implementing health IT would not lead to improvements without also evaluating and adapting the clinical workflow, the Inland NW Beacon provided clinic workflow redesign consultations. This process has been especially important given that clinics are rapidly deploying new EHRs, sometimes without making the necessary workflow adjustments to take advantage of new EHR capabilities. 
These training and education opportunities enable all team members to support clinical transformation through optimal use of new care management workflows.

\section{Evaluating the success of care management}

Another major challenge surfaced in evaluating the effectiveness of care management programs. The Beacon Communities approached care management program evaluation using a variety of data sources, IT tools, and process, outcome, and patient-reported measures. (The Beacon Community teams are working on sharing the results of these evaluations in separate publications.) However, as the programs are multifaceted and implemented in real-world community settings, identifying appropriate measures and securing needed data sources to assess impact has proved difficult. For instance, although Southeast Michigan is extracting EHR data to track high-impact diabetes measures (eg, HbAlc testing, lowdensity lipoprotein testing, eye exams, blood pressure values), patients seen at $\mathrm{FQHCs}$ and private practices are exposed to multiple diabetes-related interventions, making it difficult to attribute improvements to any individual intervention. Furthermore, the lack of standards and interoperability has hindered the Beacons' ability to readily access valid data from important sources (eg, EHRs), often requiring them to rely on less clinically detailed measures and data sources, such as patient surveys and claims data.

\section{Funding and sustainability for care management}

As the fee-for-service system generally does not reimburse clinicians or other care team members for care management activities, Beacons have used their grant funding to support these programs. Some Beacons operate in delivery systems that already have implemented pay for performance or other payment models that incentivize care management, and many are incorporating care management into their strategies to achieve Meaningful Use incentives, PatientCentered Medical Home certification, Accountable Care Organization (ACO) status, and/or participation in the Centers for Medicare and Medicaid Services Comprehensive Primary Care Initiative. At present, however, these initiatives represent competing priorities for clinic staff, time, and resources, and there is no clear path for crossprogram coordination.

Other communities are developing and marketing a "package" of core and optional care management tools and services to clinicians and hospitals, while still others are working with health plans to support their programs. The Southern Piedmont Beacon is unique in that the technology is being integrated with existing state-level infrastructure, which will facilitate its long-term sustainability and make resources created for the 3 Beacon counties available across the state. For other Beacons, the path forward is less clear; although the Beacon Program has provided unique opportunities to test innovative care management approaches, their long-term sustainability will hinge on fundamental changes to the payment system.

\section{Conclusions and Policy Implications}

While striving to deliver standardized, high-quality care in diverse contexts, all 6 Beacon Communities achieved milestones and encountered barriers. Many of these challenges stem from the competing priorities inherent in a highly dynamic policy environment, as providers are devoting significant resources to updating their technical systems and workflows to qualify for Meaningful Use incentives and/or achieve ACO status, leaving little time or resources to devote to other initiatives. As full implementation of Meaningful Use Stages 2 and 3 continue over the coming years, policymakers and providers can learn from the Beacon experiences and hopefully anticipate and attempt to mitigate the challenges of working on multiple care delivery reform efforts simultaneously.

Payment reform also will be a crucial enabler of care management program implementation. All Beacons acknowledged that financing their care management program in the current fee-for-service environment was extremely difficult. Grant programs have provided unique opportunities to test innovative approaches to care management from which other communities may learn. However, absent payment reform, these approaches may not be sustainable in the long term or scalable to other patient populations and geographic locations.

Lastly, nationwide, health care reform and quality improvement efforts are striving for standardization and adherence to best practices and clinical guidelines. The Beacon experience highlights ways in which communities can and should work toward increased standardization in certain elements of care management, particularly data standardization, system interoperability, and health information exchange. However, the diversity of these care management programs demonstrates that there is no onesize-fits-all approach to care management; rather, each community's approach must "fit" the community context and available resources.

\section{Author Disclosure Statement}

Drs. Allen, Heider, Lobach, Singh, and Sorondo, Ms. Des Jardins, Ms. Kanger, Ms. McWilliams, Ms. Polello, Ms. Rein, Ms. Schachter, Ms. Tulikangas, and Mr. Turske declared no conflicts of interest with respect to the research, authorship, and/or publication of this article.

The authors received the following financial support for the research, authorship, and/or publication of this article: Support for the development of this article was provided by the Office of National Coordinator for Health Information Technology Beacon Community Cooperative Agreement Program. The opinions, findings, and conclusions or recommendations expressed here are those of the authors and do not necessarily reflect the views of the United States government.

\section{Acknowledgments}

The authors would like to acknowledge the following individuals and organizations for their support of this collaborative writing effort: Anjum Khurshid, MBBS, PhD, MPAff, and Maria Ludwick, MBA, MPH, of the Crescent City Beacon Community; Jac Davies, MS, $\mathrm{MPH}$, and Douglas L. Weeks, PhD, of the Beacon Community of the Inland Northwest; the Bangor Beacon Community team; HealthInfoNet; Nancy Maloney, MBA, of HEALTHELINK. 


\section{References}

1. Berwick DM, Nolan TW, Whittington J. The triple aim: care, health, and cost. Health Aff (Millwood) 2008;27:759_ 769.

2. Schoen C, Osborn R, Squires D, Doty M, Pierson R, Applebaum S. New 2011 survey of patients with complex care needs in eleven countries finds that care is often poorly coordinated. Health Aff (Millwood) 2011;30:2437-2448.

3. Center for Health Care Strategies, Inc. Care management definition and framework. Available at: < http://www.chcs .org/usr_doc/Care_Management_Framework.pdf $>$. Accessed August 28, 2013.

4. Rao S, Brammer C, McKethan A, Buntin MB. Health information technology: transforming chronic disease management and care transitions. Prim Care 2012;39:327344.
5. Michigan Department of Community Health. Diabetes in Michigan Update-2013. Available at: < http://www.michigan .gov/documents/mdch/Diabetes_in_Michigan_Update_2013_ 416620_7.pdf $>$. Accessed August 28, 2013.

6. Hibbard JH, Stockard J, Mahoney ER, Tusler M. Development of the patient activation measure (PAM): conceptualizing and measuring activation in patients and consumers. Health Serv Res 2004;39(4 pt 1):1005-1026.

Address correspondence to: Alison Rein, MS AcademyHealth 1150 17th St. NW Suite 600 Washington, DC 20036

E-mail: alison.rein@academyhealth.org 